\title{
Microstructure Features and Mechanical Properties of Double-Sided Friction Stir Welded Joints of AA2050-T84 Thick Plates
}

\author{
F. F. Santini , A. H. Plaine ${ }^{b *}$ (D), C. R. M. Afonso ${ }^{a}$, L. Bergmann ${ }^{c}$, N. G. de Alcântara ${ }^{a}$, \\ J. F. dos Santos ${ }^{c}$, M. H. Miyazakid
}

\author{
${ }^{a}$ Universidade Federal de São Carlos, Departamento de Engenharia de Materiais, Programa de \\ Pós-Graduação em Ciência e Engenharia de Materiais, Rod. Washington Luiz, km 235, 13565-905, \\ São Carlos, SP, Brasil \\ ${ }^{b}$ Universidade do Estado de Santa Catarina, Departamento de Engenharia Mecânica,Programa de \\ Pós-Graduação em Ciência e Engenharia de Materiais, Rua Paulo Malschitzki, 89219-710, Joinville, \\ $S C$, Brasil \\ 'Helmholtz-Zentrum Geesthacht, Institute of Materials Research, Materials Mechanics, Solid State \\ Joining Processes, Max-Planck-Str. 1, 21502, Geesthacht, Germany \\ ${ }^{d}$ Embraer S.A., Rod. Presidente Dutra, km 134, 12247-004, São José dos Campos, SP, Brasil
}

Received: July 13, 2020; Revised: December 02, 2020; Accepted: December 16, 2020

\begin{abstract}
As part of an ongoing process to fully assess the potential for friction stir welding (FSW) to be used in the aerospace industry, an attempt was made to produce double sided FSW joints at traverse speeds equal or higher than $5 \mathrm{~mm} / \mathrm{s}$ of AA2050-T84 $12.7 \mathrm{~mm}$ thick plates for high-volume production applications. With an emphasis on weld quality, the local and global mechanical properties were evaluated and correlated with microstructure of the welding area. Sound welds with no volumetric defects were obtained for tool traverse speeds up to $12 \mathrm{~mm} / \mathrm{s}$, resulting in yield and ultimate tensile strengths corresponding to $65 \%$ and $77 \%$ of base material, respectively. The metallurgical and mechanical characterization demonstrate that density of $\mathrm{Cu}$-rich precipitates has a first order effect on micro-hardness variation. In the stir zone the dissolution temperature of this precipitate is achieved and its volume fraction is greatly reduced. The remaining precipitates seems to be partially dissolved and undergone a significant thickening at the welding zones in which the process temperature has not reached the dissolution temperature. Weld fractures after tensile tests were observed to start in the region of hardness minima.
\end{abstract}

Keywords: DS-FSW, Friction Stir Welding, high-speed welding, aluminum-cooper-lithium alloys, mechanical performance.

\section{Introduction}

In the last decade, new aluminum alloys for aerospace applications have been developed based on the $\mathrm{Al}-\mathrm{Cu}-\mathrm{Li}$ system, presenting significant improvement in required properties for structural performance: reduction in density, stiffness increase, increasing in corrosion resistance and increasing in fracture toughness and fatigue growth resistance. Primary representatives are AA 2050, which was used in the modern Airbus fleet ${ }^{1}$ and AA 219X, which led to massive weight savings on the external tank of the space shuttle ${ }^{2}$ and was also used in the manufacturing of the first stage of Falcon 9 rockets $^{3}$. However, the difficulties in welding precipitation hardening aluminum alloys by fusion welding processes has hindered the development of new applications, opening a new avenue for the use of alternative joining technologies such as solid-state friction based-processes.

Joining of aluminum alloys via friction stir welding (FSW) has been exceedingly successful. Some of the early

*e-mail: athos.plaine@udesc.br adoption of this technology was for aerospace applications by Boeing and $\mathrm{NASA}^{4}$. A great extent of knowledge exists on the role of various FSW process parameters in obtaining defect-free high-quality welds. However, it is noticed that the mechanical properties of precipitate strengthened aluminium alloys tend to deteriorate in the weld zones as they directly depend on the dissolution and/or coarsening of strengthening second phase particles. Sidhar et al. ${ }^{5}$ investigated the precipitation and dissolution kinetics of $\mathrm{T} 1\left(\mathrm{Al}_{2} \mathrm{CuLi}\right)$ precipitates in AA 2050-T8 alloy through DSC curves. A precipitate coarsening was observed in the temperature range of $240-310^{\circ} \mathrm{C}$, while an endothermic peak between $370{ }^{\circ} \mathrm{C}$ and $460^{\circ} \mathrm{C}$ represented the range of dissolution. Taylor et al. ${ }^{6}$ mapped the heterogeneous precipitates microstructure issued from the friction stir welding of a $2050 \mathrm{Al}-\mathrm{Cu}-\mathrm{Li}$ alloy in the T8 temper. The authors have shown that the FSW process has dissolved the existing T1 precipitates in a region wider than the stir zone (SZ). Moreover, in the region adjacent to the SZ, where temperature does not reach the dissolution 
temperature, the remaining T1 precipitates partially dissolve and undergo a significant thickening. A direct correlation was observed between the precipitates and micro-hardness measurements.

For application in high-volume aerospace components production, welding speed is a significant factor influencing cost reduction. Zhang et al. ${ }^{7}$ reported that sound FSW 2219A1-T6 joints could be obtained at a welding speed as high as $800 \mathrm{~mm} / \mathrm{min}$ with a rotational rate of $800 \mathrm{rpm}$ by adjusting the plunge depth, and the tensile strength of the FSW joints was further increased at $800 \mathrm{~mm} / \mathrm{min}$. Nevertheless, some other studies indicate that void defects are easily formed at higher welding speeds ${ }^{8-10}$. Thus, with few exceptions, the majority of available data for aluminum blanks produced via FSW were produced at welding speeds below $5 \mathrm{~mm} / \mathrm{s}$.

The focus of this work was to produce and characterize double sided friction stir welds (DS-FSW) at traverse speeds equal or higher than $5 \mathrm{~mm} / \mathrm{s}$ of AA2050-T84 $12.7 \mathrm{~mm}$ thick plates that could further enable greater use of mass-saving aluminum alloys in aerospace applications. The plates were welded from both sides to minimize the thermal cycles involved in the process. Based on the results, the relationship between weld microstructure and mechanical properties was discussed.

\section{Experimental Procedure}

AA 2050-T84 $12.7 \mathrm{~mm}$ thick plates were used as the parent metal in this investigation and its chemical composition is shown in Table 1. The FSW tool used comprises a $20 \mathrm{~mm}$ diameter flat scrolled shoulder with an $8 \mathrm{~mm}$ length conical threaded probe with three flats, as shown in Figure 1, both made of high temperature resistant steel. As shown in Table 2, $400 \mathrm{~mm}$ long welds were produced in butt joint configuration for eight different welding conditions, using a computer numerical controlled friction stir welding machine, with a welding direction perpendicular to the rolling direction of the plate. The variation ranges of each welding parameter (tool rotational speed (RS) and traverse speed (TS)) were established based on few studies present in literature ${ }^{11-13}$ and empirical trials, always keeping the traverse speed equal or higher than $5 \mathrm{~mm} / \mathrm{s}$. Material flow and mechanical properties were evaluated as a ratio of welding speed to rotational rate, also known as weld pitch (WP). This is an important parameter for FSW joints associated with the specific weld energy (Joule/meter), i.e., the energy generated per unit length of weld decreases with increasing weld pitch.

Temperature measurements were performed during the DS-FSW process to quantify and correlate the different levels of energy input with the microstructure features and mechanical behavior of the welds. These measurements were carried out employing a data acquisition system from National Instruments in combination with the LabView software, within k-type thermocouples (nickel-chrome/ nickel-aluminum) placed about $6.5 \mathrm{~mm}$ under the surface of the backing plate, at three different positions along the welding direction. In each position the thermocouples were placed 25, 22 and $17 \mathrm{~mm}$ away from the weld center, as shown in Figure 2, in order to obtain the temperature profiles in different weld zones under the FSW tool.

Moreover, the energy input values from the friction between the tool shoulder and the workpiece and material transport were also calculated based on the machine outputs by using the following Equation $1^{14}$ :

$$
E=(2 \pi T \omega) / v
$$

where $\mathrm{T}$ is the torque, $\omega$ is the too rotational speed and $v$ is the tool traverse speed.

Table 1. Chemical composition of parent metal (\%wt.).

\begin{tabular}{cccccccccc}
\hline $\mathrm{Cu}$ & $\mathrm{Li}$ & $\mathrm{Mg}$ & $\mathrm{Fe}$ & $\mathrm{Si}$ & $\mathrm{Zn}$ & $\mathrm{Mn}$ & $\mathrm{Ag}$ & $\mathrm{Zr}$ & $\mathrm{Al}$ \\
\hline 3.7 & 1.0 & 0.3 & 0.05 & 0.03 & 0.09 & 0.32 & 0.5 & 0.09 & $\mathrm{Bal}$ \\
\hline
\end{tabular}

Table 2. DS-FSW experimental parameters used in this study.

\begin{tabular}{cccc}
\hline Condition & RS (rpm) & TS $(\mathrm{mm} / \mathrm{s})$ & Weld pitch $(\mathrm{mm} / \mathrm{rev})$ \\
\cline { 1 - 1 } \cline { 3 - 4 } & \multirow{2}{*}{400} & 4 & 0.60 \\
\cline { 3 - 4 } 2 & & 6 & 0.90 \\
\hline 3 & 500 & 8 & 0.96 \\
\hline 4 & 600 & 10 & 1.00 \\
\hline 5 & 700 & 12 & 1.03 \\
\hline 6 & \multirow{2}{*}{400} & 7 & 1.05 \\
\cline { 1 - 1 } $7^{*}$ & & 8 & 1.20 \\
\hline $8^{*}$ & 500 & 10 &
\end{tabular}

\footnotetext{
*Probe failure
}

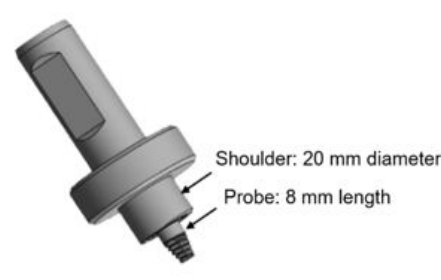

(a)

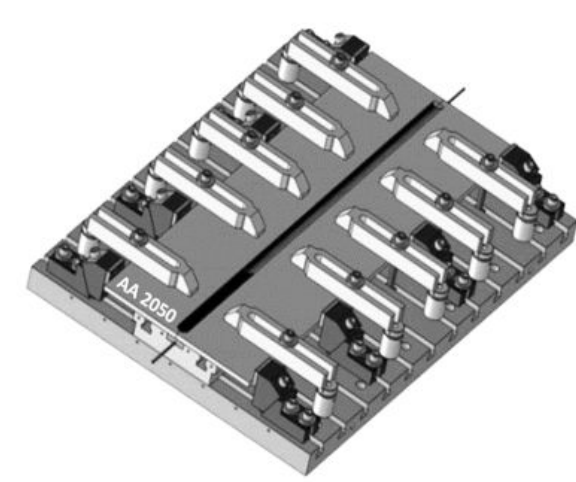

(b)

Figure 1. Schematic illustration of (a) the AA 2050-T84 butt joint configuration and the fixture table. (b) The threaded conical FSW tool. 


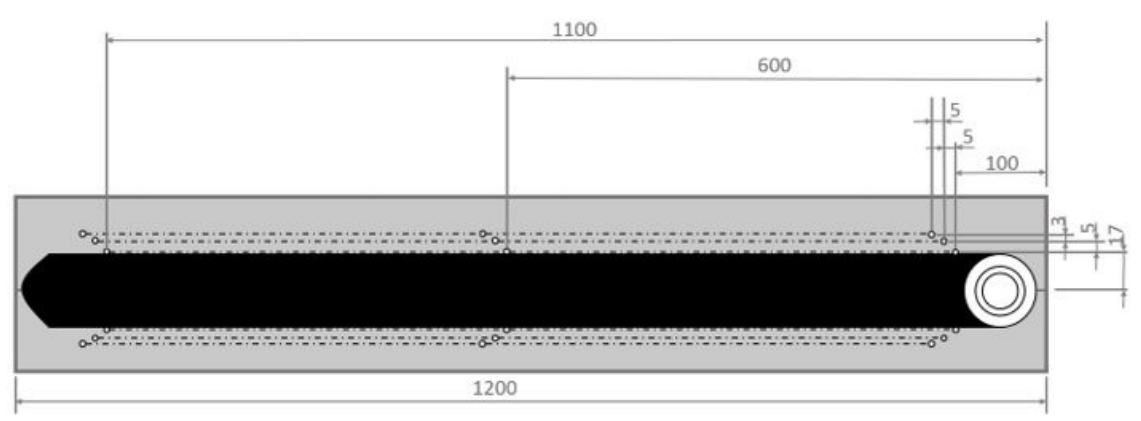

Figure 2. Scheme of the FSW joint showing the position of the thermocouples for the temperature measurements in the workpiece (All dimensions are in millimeters).

The cross-section of the joints was analyzed using an optical microscope (DM IR microscope, Leica) under reflective light and a FEI Quanta 650 scanning electron microscope fitted with an EDAX energy dispersive X-ray spectrometer (EDS). The joints were previously cut on nearby the weld center in the cross section and embedded in Demotec 30 powder and liquid followed by standard grinding and polishing procedures.

Vickers micro-hardness was carried out with a conventional Vickers indenter with a 20-gf load and $10 \mathrm{~s}$ dwell time (Zwick Roell ZHV). Micro-hardness profiles were determined from mid-thickness across the section perpendicular to the welding direction. Tensile tests were performed at room temperature at a tool traverse speed of $1.0 \mathrm{~mm} / \mathrm{min}$. All test-specimens were extracted by spark erosion along the transverse direction, in order to avoid any effect of texture in the parent plate.

\section{Results and Discussion}

Figure 3 shows an inverse correlation of WP with the corresponding energy input (E), calculated according to Equation 1, with values ranging from 0.60 to $1.20 \mathrm{~mm} / \mathrm{rev}$ and from 1.20 to $0.60 \mathrm{~kJ} / \mathrm{mm}$, respectively. Here it is worth to mention that WP below $0.6 \mathrm{~mm} / \mathrm{rev}$ requires very high rotational speeds to obtain traversing speeds equal to or higher than $5 \mathrm{~mm} / \mathrm{s}$, causing excessive material softening and flash generation. On the other hand, WP beyond $1.2 \mathrm{~mm} / \mathrm{rev}$ values led to an insufficient heat generation and an inadequate material mixing to produce sound welds. Moreover, at a WP of $1.2 \mathrm{~mm} / \mathrm{rev}$, the DS-FSW tool probe broke due to the high stress levels experienced during the welding process. Therefore, the WP variation range was set between 0.6 and $1.05 \mathrm{~mm} / \mathrm{rev}$, for the chosen tool and material.

Temperature measurements were performed for the lowest energy input welding condition (condition 5), at 17, 22 and $25 \mathrm{~mm}$ from the center line of the welds, as schematically shown in Figure 2. A linear regression was then used to model the relationship between temperature and transverse position, starting from the weld center, in order to estimate the peak temperatures exactly in the different welding zones. Figure 4 shows the measured and estimated peak temperatures. The maximum temperature in the HAZ (located at $7.0 \mathrm{~mm}$ from the joint center line) and TMAZ (located at $2.5 \mathrm{~mm}$ from the joint center line) were set to be approximately $355^{\circ} \mathrm{C}$ and $390^{\circ} \mathrm{C}$, respectively. At these temperatures, as previously mentioned, the precipitates are

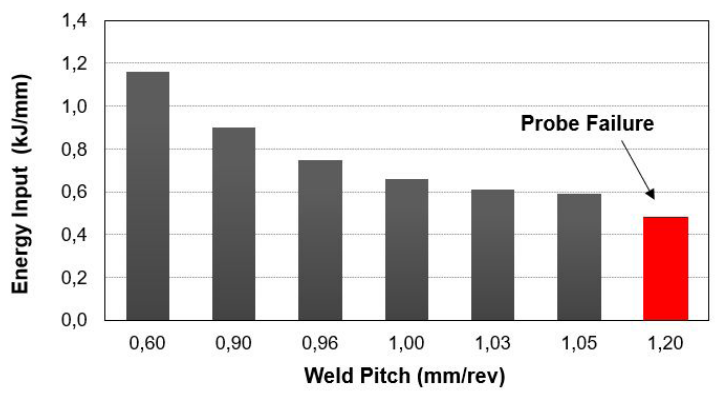

Figure 3. Correlation between weld pitch (tool linear speed/tool rotational speed) and energy input (calculated from Equation 1) for the different welding conditions used in this work.

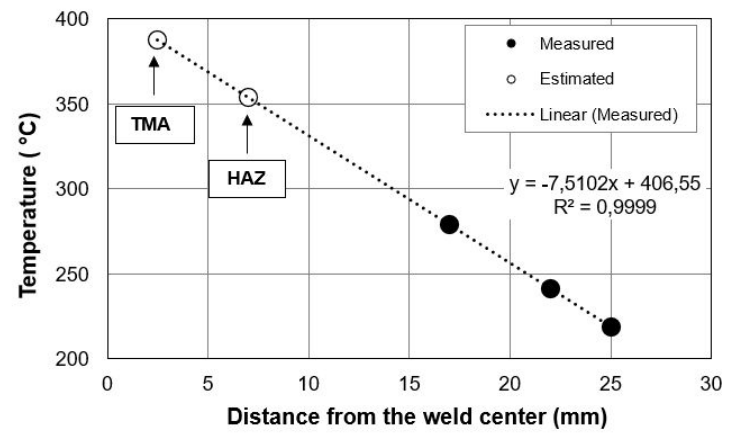

Figure 4. Measured and estimated process peak temperatures for different distances from the weld center of the AA2050 joint processed with a low energy input (welding condition 5).

able to coarsen and partially dissolve. Moreover, since the other welding conditions have higher values of energy input than welding condition 5 , it is expected that the coarsening and dissolution of the precipitates takes place in a larger area.

Figure 5 shows a typical joint segment, representative of the plane transverse to the weld travel direction taken from welding condition 5 . The macrograph easily reveals the geometry of the weld seam, as well as the plastic flow tendency in the nugget zone, indicating full penetration and no apparent defects. Volumetric defects were only observed for welding condition 6, with the lowest energy input (Figure 6). In this case, the high level of travel speed gives less amount of work per unit of length to the workpiece and, as a result, 
it leads to less plasticization of the material, becoming more difficult to be forged and consolidated by the tool shoulder.

A typical DS-FSW microstructure is commonly divided into zones, Figure 7, affected by different thermal cycles and degrees of deformation. The microstructure of the center of the welds, known as the stir zone (SZ), undergoes the highest amount of deformation and thermal cycle and it is characterized by a recrystallized grain structure (Figure $5 \mathrm{c}$ ). In contrast, surrounding the SZ, the thermomechanically affected zone (TMAZ) were characterized by a high degree of deformation and rotation of the base material pancakelike grains (Figure 5a-b). The heat affected zone (HAZ), in turn, shows no apparent difference from the base material.

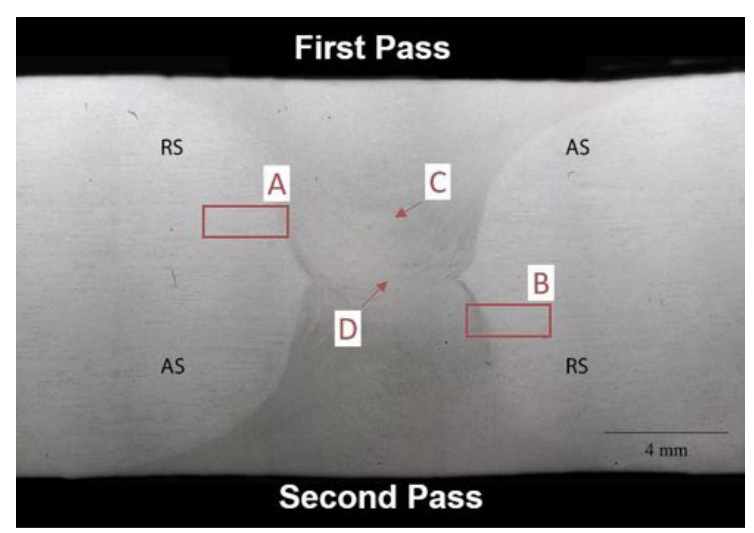

Figure 5. Macroscopic view of a representative joint of AA2050-T84 joint. AS and RS are the short writings for advancing and retreating side, respectively, and the regions indicated as A, B, C and D are shown in higher magnifications in Figure 6.
However, in age-hardened alloys the hardness level typically decreases in this zone, clearly indicating that the thermal cycle during the welding process has a significant influence on fully aged alloys, either by overaging or by decreasing dislocation density, or probably by both. In addition, the middle of the welded joint, also known as double stir zone (DSZ), in which the second welding pass overlaps the first one, the material locally experiences two thermal cycles and is also more deformed, leading to a greater microstructure refinement (Figure 5d). Muzvidziwa et al. ${ }^{15}$ suggests that the DSZ grain size refinement is not only peak temperature dependent, but it is also initial grain size dependent due to re-stirring of the recrystallized grains.

To better understand the local structural modifications in the HAZ and SZ, EBSD scans were performed along different welding zones (Figure 8). The presence of subgrains in the HAZ (highlighted by black arrows in Figure 8b) evidences the formation of the dislocation walls, which is a product of local dynamic recovery caused by the combination of pre-deformed grains and the thermal influence of the processing. In this case, the high stacking fault energy in $\mathrm{Al}$ alloys facilitates dislocation climb and cross-slip, lowering the accumulated internal energy of the material. Figure $8 \mathrm{c}$ shows that the weld center has only equiaxed grains, which is a feature of full recrystallization due to the relatively high local shear strain in this specific zone.

EDS X-ray elemental mapping of $\mathrm{Cu}-\mathrm{K}$ was performed to give an indication the microstructural evolution of $\mathrm{Cu}$-rich precipitates, as a result of the spatial variation of temperature and strain history within the different welding zones. Figure 9a shows that the BM microstructure consists in a fine dispersion of thin precipitates homogeneously distributed within the
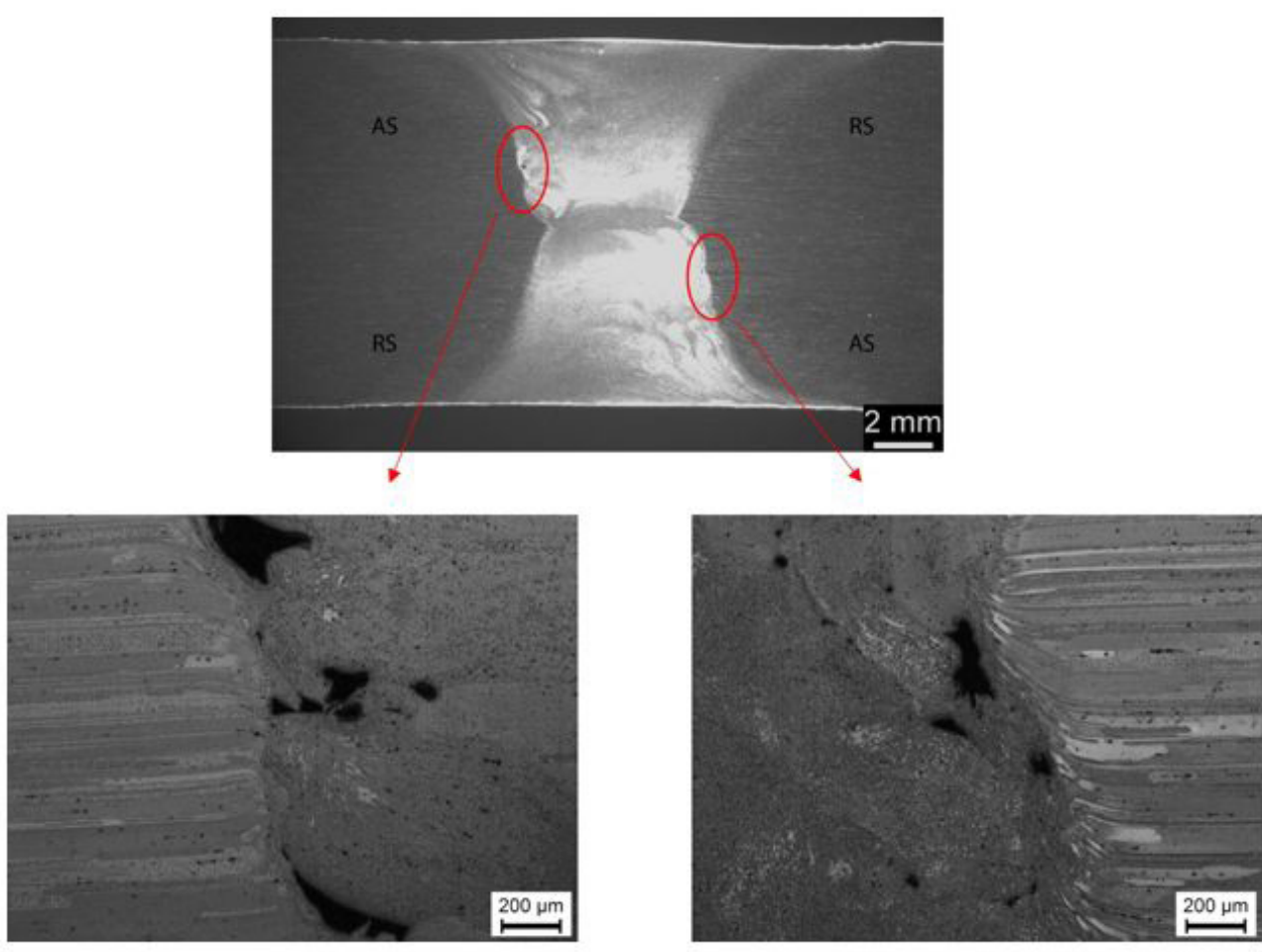

Figure 6. Volumetric defects of AA2050-T84 joints processed with the lowest energy input (welding condition 6). 


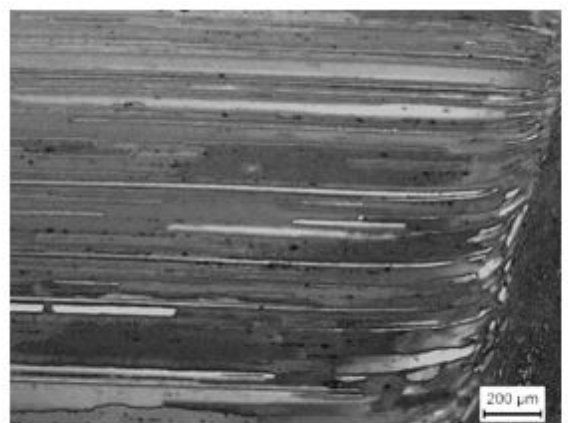

(a)

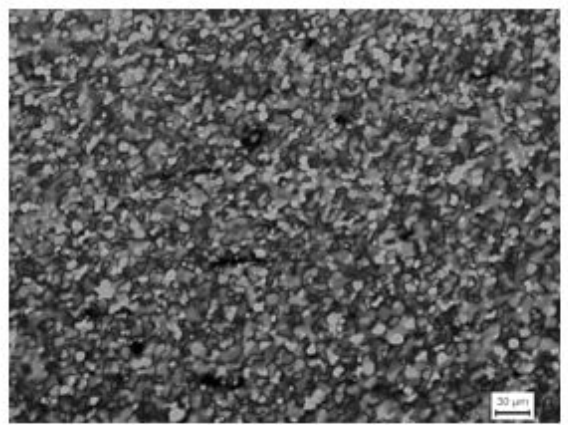

(c)

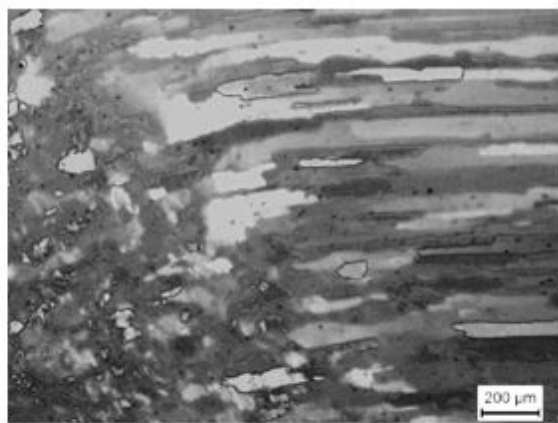

(b)

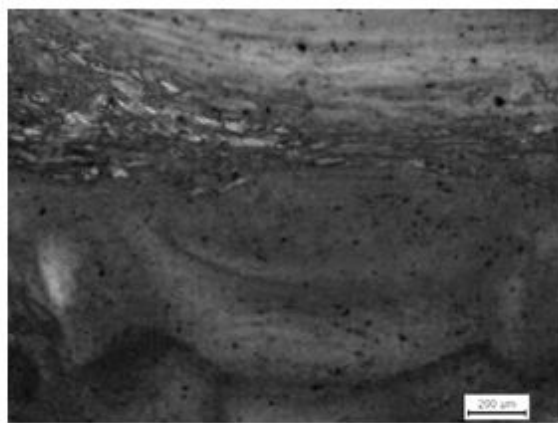

(d)

Figure 7. Higher magnification of regions marked as A, B, C and D as in Figure 4, showing different microstructural features in the welding area.

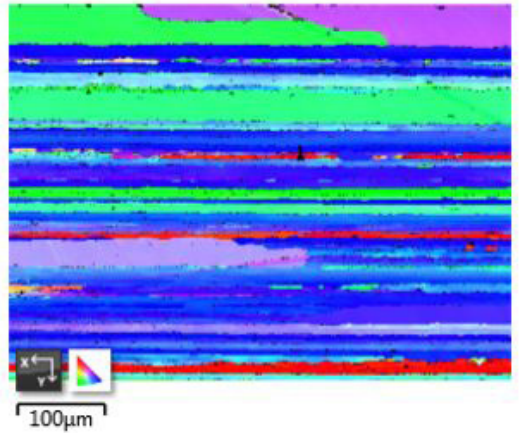

(a)

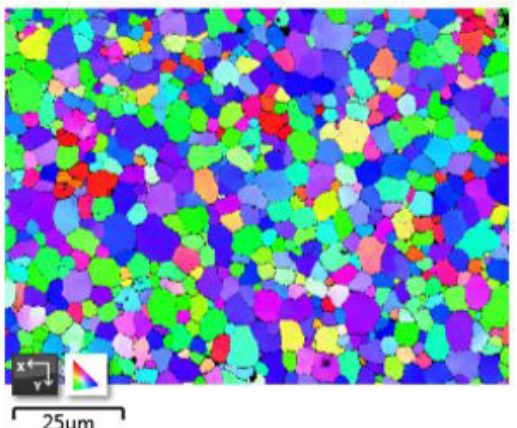

(c)

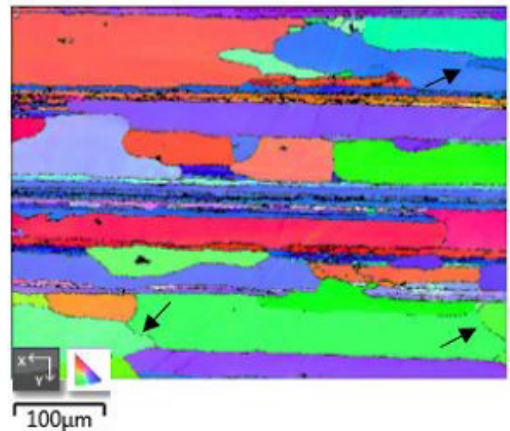

(b)

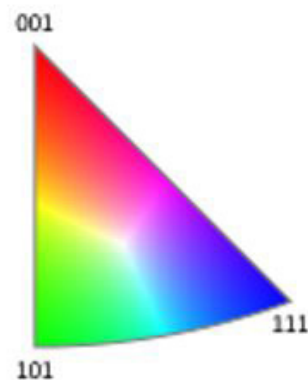

(d)

Figure 8. EBSD maps of different welding zones: (a) BM, (b) HAZ, (c) SZ and (d) crystallographic reference. Black arrows in (c) indicated the formation of subgrains in the HAZ. 


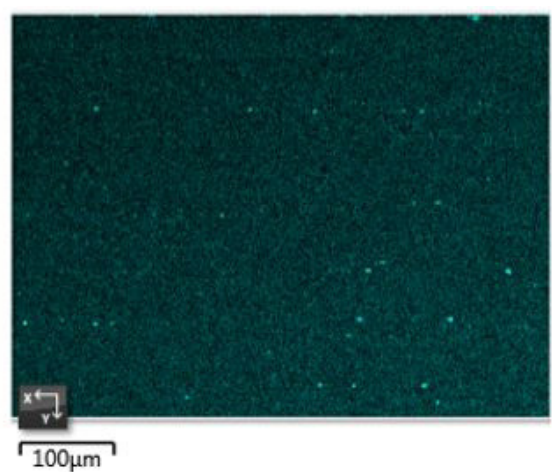

(a)

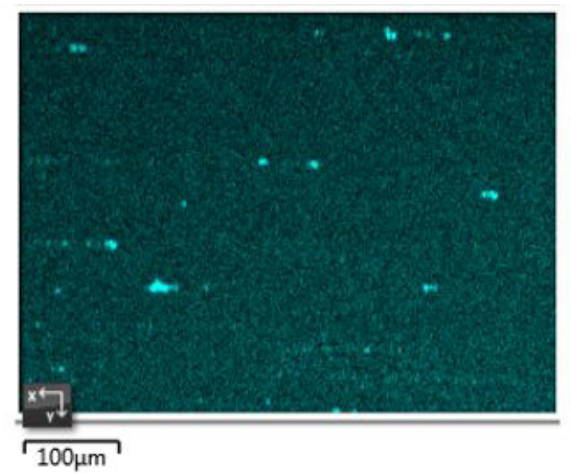

(b)

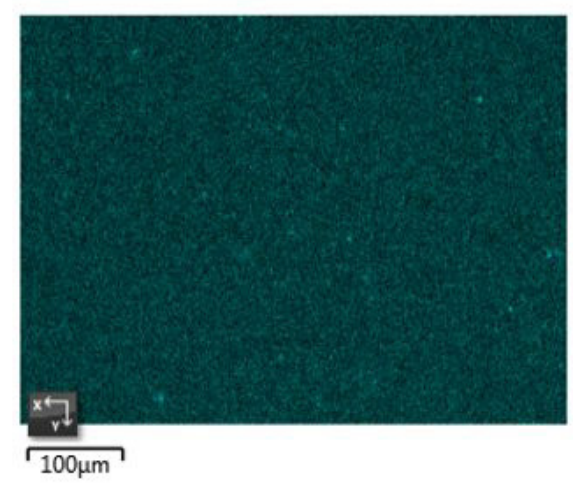

(c)

Figure 9. EDS X-ray elemental mapping of Cu-K of different welding zones: (a) BM, (b) HAZ and (c) SZ; indicating the microstructural evolution of $\mathrm{Cu}$-rich precipitates.

grains. In the HAZ, such precipitates present a different length, thickness and volume fraction than in the base material (Figure 9b). Close from the weld center, the volume fraction of the precipitates is significantly to decreased, as shown in the Figure 9c. By directly comparing Figure 9 with the estimated temperatures of each welding zone (Figure 4), it evidences that a short stay at temperature below $300^{\circ} \mathrm{C}$ could not modify the precipitates microstructure (BM). Although, for a temperature range between $300-400{ }^{\circ} \mathrm{C}$ (experienced by the HAZ, TMAZ and SZ), the precipitates might coarsen and partially dissolve and, as a consequence, locally modify the mechanical properties of the alloy (2).

To correlate precipitates size and distribution with the local mechanical properties, micro-hardness profiles were obtained from mid-thickness across the section perpendicular to the welding direction of the AA2050-T84 joints DS-FSW produced with high and low energy inputs (Figure 10). The typical "W" shape is only clearly for the highest energy input welding condition (condition 1), which points out a minimum hardness at the TMAZ, presenting values of $104 \mathrm{HV}$ and increasing in the SZ to about $125 \mathrm{HV}$. The hardness values tend to decrease in the SZ with a decrease in the E, attaining a value of about $106 \mathrm{HV}$ for the low $\mathrm{E}$ welding condition (condition 6) specimen. In addition, it can be seen there is less hardness loss in the welded zones when compared with average hardness values from the BM (166 HV). It is important to note that the minimum hardness values found in the TMAZ are approximately equivalent for both sides of the FSW joints (advancing and retreating sides). Such symmetry could be attributed to the double sided FSW process, which results in a more homogeneous plastic flow and temperature distribution. Moreover, the spacial correspondence between Figure 9 and Figure 10 demonstrates a direct correlation between the precipitation state and the micro-hardness, suggesting that only the temperature excursion is responsible for the welding zones mechanical resistance and that the observed grain refinement has only marginal effect, except for SZ. In this zone, due to the apparent dissolution of the precipitates, grain size becomes the main factor influencing local mechanical properties.

Figure 11 presents the tensile properties for all welding conditions and BM. Results are presented in terms of yield strength (YS), ultimate strength (US) and ductility. The results show a similar performance for all the different welding conditions, with a slightly trend to an increase in strength by increasing WP (except for condition 6 , in which volumetric defects were observed), attaining maximum yield and tensile strength values to $67 \%$ and $76 \%$ of the $\mathrm{BM}$ values, respectively. Interesting, the ductility values also decreased, ranging from $5 \%$ to $2 \%$ by decreasing $\mathrm{E}$. The general trend to an increase in strength and a decrease percentage elongation with increasing WP (or decreasing E) 


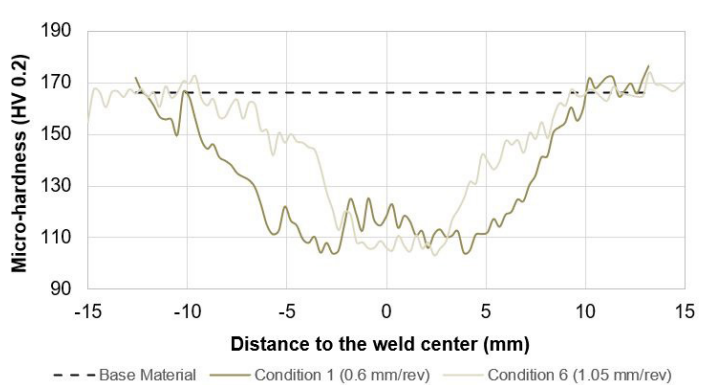

Figure 10. (a) Mid-thickness hardness profiles of the transversal cross-section surface of the joints produced with the highest (welding condition 1) and lowest (welding condition 6) energy inputs.

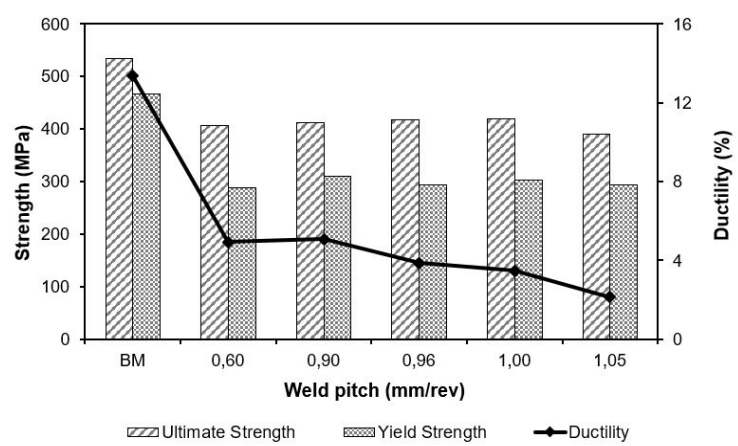

Figure 11. Tensile properties for different welding conditions and $\mathrm{BM}$, showing yield strength (YS), ultimate tensile strength (US) and elongation values.

was also observed by Shukla et al. ${ }^{16}$ evaluating the effects of the FSW process parameters on the microstructure and mechanical properties in $1 \mathrm{~mm}$ thick 2024-T3 aluminum alloy. The authors reported that for high values of $\mathrm{E}$, the weld fractures always occurred in the region of hardness minima. In the present work, a similar fracture behavior was observed. Although, for lower E conditions, a tendency to approximation of the fracture to the SZ was observed, which might be explained in terms of higher stress concentration, due to the higher strain rate, in conjunction with a lower thermocycle at the TMAZ close to the SZ in low E joints. Moreover, the greater precipitate coalescence and dissolution, promoted by the joints of high E, extends the softening region through to the HAZ in opposite direction to the SZ, as previously observed.

\section{Conclusions}

The feasibility of producing double sided friction stir welds of AA2050-T84 $12.7 \mathrm{~mm}$ thick plates at traversing speeds equal or higher than $5 \mathrm{~mm} / \mathrm{s}$ were successful investigated in this study. Sound joints with no volumetric defects were obtained for traversing speeds up to $12 \mathrm{~mm} / \mathrm{s}$, resulting in yield strength and ultimate tensile strength of $65 \%$ and $77 \%$ of the base material values, respectively. For the material and dimensions chosen, welding pitch variation range has to be set between $0.6 \mathrm{~mm} / \mathrm{rev}$ and $1.05 \mathrm{~mm} / \mathrm{rev}$ in order to avoid excessive material softening and flash generation or probe failure. The density of $\mathrm{Cu}$-rich precipitates, which decreases with the distance from the weld surface, has a first order effect on both local and global mechanical properties. Minimum hardness values were found near to the SZ/TMAZ boundary, in which the weld fracture after tensile tests were predominantly observed.

\section{Acknowledgments}

This study was financed in part by the Coordenação de Aperfeiçoamento de Pessoal de Nível Superior - Brasil (CAPES) - Finance Code 001.

\section{References}

1. Prasad CE, Gokhale A, Wanhill RJH. Aluminum-lithium alloys Reino Unido: Butterworth-Heinemann; 2014. p. 27-58.

2. Nasa. Super lightweight external tank. Washington: NASA; 2005. NASA Facts.

3. Niedzinski M, Thompson C. Airware 2198 backbone of the falcon family of SpaceX launchers. Light Met Age. 2010;68:6-7.

4. Jones C, Adams G. Assembly of a full-scale external tank barrel section using friction stir welding. In: International Symposium on Friction Stir Welding (1ISFSW); 1999 June 14-16; Thousand Oaks, California. Cambridge: The Welding Institute; 1999.

5. Sidhar H, Mishra RS, Reynolds AP, Baumann JA. Impact of thermal management on post weld heat treatment efficacy in friction stir welded 2050-T3 alloy. J Alloys Compd. 2017;722:3308 .

6. Taylor P, De Geuser F, Malard B. Microstructure mapping of a friction stir welded AA2050 Al $-\mathrm{Li}-\mathrm{Cu}$ in the T8 state. Philos Mag. 2014;94(13):1451-62.

7. Zhang Z, Xiao BL, Ma ZY. Effect of welding parameters on microstructure and mechanical properties of friction stir welded 2219Al-T6 joints. J Mater Sci. 2012;47:4075-86.

8. Xu WF, Liu HJ, Luan GH, Dong CL. Microstructure and mechanical properties of friction stir welded joints in 2219-T6 aluminum alloy. Mater Des. 2009;30:3460-7.

9. Sharma C, Dwivedi DK, Kumar P. Influence of in-process cooling on tensile on tensile behaviour of friction stir welded joints of AA7039. Mater Sci Eng A. 2012;556:479-87.

10. Zhang HJ, Liu HJ, Yu L. Effect of water cooling on the performances of friction stir welding heat-affected zone. J Mater Eng Perform. 2012;21:1182-7.

11. Proton V, Alexis J, Andrieu E, Delfosse J, Lafont MC, Blanc C. Characterisation and understanding of the corrosion behaviour of the nugget in a 2050 aluminium alloy Friction Stir Welding joint. Corros Sci. 2013;73:130-42.

12. Fendoni A. Effect of post weld heat treatment on the corrosion behaviour of a AA2050T34 [dissertation]. Birmingham: University of Birmingham; 2010.

13. Pouget G, Reynolds AP. Residual stress and microstructure effects on fatigue crack growth in AA2050 friction stir welds. Int J Fatigue. 2008;30(3):463-72.

14. Campo KN, Campanelli LC, Bergmann L, Santos JF, Bolfarini C. Microstructure and interface characterization of dissimilar friction stir welded lap joints between Ti-6Al-4V and AISI 304. Mater Des. 2014;56:39-45.

15. Muzvidziwa M, Okazaki M, Yamagishi S, Seino M. Local fatigue crack propagation behavior of a two-pass friction stir welded aluminum alloy. Solid Mechanics and Materials Engineering. 2014;1(6):1-9.

16. Shukla AK, Baeslack WA. Study of microstructural evolution in friction-stir welded thin-sheet $\mathrm{Al}-\mathrm{Cu}-\mathrm{Li}$ alloy using transmission-electron microscopy. Scr Mater. 2007;56:513-6. 